\title{
The Evolution of Nonlinear Dynamics in Political Science and Public Administration: Methods, Modeling and Momentum
}

\author{
L. DOUGLAS KIEL* \\ Professor of Public Administration and Political Economy, School of Social Sciences, \\ University of Texas at Dallas, P.O. Box 830688, Richardson, TX 75083
}

(Received 2 February 2000)

Evolution is never total adaptation. It always requires destabilization, the reaching out, the self-presentation which offers new symbiotic relations, the risk accompanying innovation. ${ }^{\dagger}$

\begin{abstract}
This paper examines the evolution of the application of nonlinear dynamics and related methods to the study of political science and public administration throughout the 20th century. Some analysts understood the importance of nonlinearity to political and administrative studies in the early part of the century. More recently, a growing number of scholars understand that the political and administrative worlds are ripe with nonlinearity and thus amenable to nonlinear dynamical techniques and models. The current state of the application of both discrete and continuous time models in political science and public administration are presented. There is growing momentum in political and public administration studies that may serve to enhance the realism and applicability of these sciences to a nonlinear world.
\end{abstract}

Keywords: Political science; Public administration; Public policy; Research methods; Nonlinearity; Complexity; Discrete time models; Continuous time models

It is often difficult to determine if innovation in the academic enterprise is the result of courageous intent, tempered sagacity, or simple dumb luck by those with too much time on their hands. Clearly though, one variable related to innovation is that such novelty is generally produced by a small group that manages to extricate itself from the dominance of the existing intellectual paradigm. In short, evolution occurs along the periphery.

This paper explores and presents the results of such an evolutionary process. Specifically, this paper examines the evolution and current state of the application of nonlinear dynamics to the phenomena of political science and public

*Tel.: (972)-883-2019, Fax: (972) 883-2019, e-mail: dkiel@utdallas.edu

${ }^{\dagger}$ Erich Jantsch, The Self-Organizing Universe, 1980. 
administration during the 20th century. This evolution is the result of a small group of innovators in the fields of political science and public administration who are just beginning to see their work disperse among a larger number of interested scholars.

When examining the evolution of an academic enterprise it is always of value to remember the Kuhnian warning concerning intellectual revolutions (Kuhn, 1962). In brief, the incursions of the emergent paradigm will always be slowed by the weight of the existing convention. Given the fact that political science and public administration are still relatively immature as "mathematical enterprises" any new method can be seen as either a threat to or an opportunity for the existing body of methodological tools. Clearly though the dominant assumptions concerning dynamics in these fields have been those of linear relationships and stable dynamics. This reality is more a result of the relative state of statistical and mathematical sophistication among scholars in these fields than it is a failure to appreciate the potential for nonlinearity, instability and uncertainty in political and administrative phenomena.

This paper is organized into four sections. The first section explores the evolution of considering and examining nonlinearity in political and public administrative phenomena. The second section details the array of nonlinear methods currently employed in political and public administrative research. These methods cross the categories of temporal, spatial and functional nonlinearity. The next section presents previously published nonlinear mathematical models of political and public administrative phenomena. The mathematics of the dynamic models presented focus on the more complex models and methods developed in the fields. This third section also introduces the current debate among political scientists as to the relative value of discrete versus continuous time models of political phenomena. Finally, an effort is made to discern the prospects for the further evolution of nonlinear methods in understanding political and public administrative phenomena.

\section{THE EVOLUTION OF THE RECOGNITION OF NONLINEARITY IN POLITICAL SCIENCE AND PUBLIC ADMINISTRATION}

\section{Early Recognition of Nonlinearity}

Some early 20th century social scientists were cognizant of the possibility of nonlinearity in political and public administrative phenomena. As early as 1928 the quantitative literature in political science evidenced the recognition of the possibility of nonlinearity in data relevant to the study of politics. Stuart Rice's, Quantitative Methods in Politics (1928, p. 106) revealed his appreciation for the likelihood of the nonlinear nature of the diffusion of political attitudes or what he labeled "the velocity of diffusion". Rice's language is hauntingly similar to more recent studies investigating contagion effects in attitudinal formation. Rice accepted the limitations of the then state of the art in social statistics to contend with nonlinearity by noting that he was "merely.. suggesting one direction in which statistical methods of determining variability may yet throw light upon an important social and political phenomenon" (Rice, 1928, p. 107).

Efforts to discover early evidence of the recognition of nonlinearity in the literature of public administration resulted in Nobel Laureate Herbert Simon's (1957) appreciation for the nonlinear nature of human behavior. Simon's book, Models of Man: Mathematical Essays on Rational Behavior in a Social Setting (1957), is comprised of sixteen of his essays that appeared in previously published journal articles. Simon's interest in administration early in his career, in fact his Ph.D. work and early career were devoted to public administration, is evidenced in the books organization into sections including topics such as "motivation: inducements and contributions" and "rationality and administrative decision-making".

Simon was concerned with the interactions of "social groups" and the effects of outside 
influences on the maintenance of these groups. He assumed nonlinear relationships between the "friendliness" of groups and the "amount of activity" of the group as a saturation phenomena in which increased friendliness resulted in diminishing rates of activity. Simon's mathematical model was defined via the continuous dynamics of a system of differential equations. It is worthy of note that, while rigorous assumptions concerning nonlinearity are seen as a recent event, Simon recognized the importance of nonlinearity as a major factor in altering system dynamics as early as the 1950s.

\section{The Behavioral Revolution and Recent Advances in Modeling Nonlinear Dynamics Systems}

The behavioral revolution in the social sciences after World War II had a profound impact on both political science and public administration. This behavioral or quantitative revolution brought statistical rigor to fields that had relied previously on normative debate. Much of the immediate postWar effort was aimed at simply quantifying or statistically verifying questions of "What exists?". Yet, both of these fields were greatly strengthened by efforts to move them away from the mere espousal of theory to at least offering the potential for the actual testing of theory.

Many of the methodological advances in political science and public administration during the decades of the 1960's and 1970's involved the proliferation of traditional statistical techniques and methods of ordinary least squares linear modeling. While political science and public administration did not attempt to emulate the natural sciences to the same extent as their economics brethren, most political scientists and public administrationists did pursue a mechanical and linear statistical paradigm similar to the "physics envy" attributed to economists (Mirowski, 1989).

One widely recognized effort to produce mathematical models of political behavior was Lewis Fry Richardson's examination of arms races
(Richardson, 1960a, 1960b). Richardson's research was driven by the historical recognition that WW I occurred although the participating nations seemed not to want war. Richardson thus saw the conflict as the result of dynamics in the international "system" that dominated even the intentions of political leadership groups. This early modeling effort thus focused on the "system effects" of arms build-ups and the action-reaction sequence taken by adversaries.

Richardson's work on arms races is also of particular interest because it signaled the gap between the theoretical recognition of nonlinearity and the computational limitations of much of 20th century social science. Richardson's theoretical models suggested nonlinear specifications due to assumptions of perceived threat levels of an adversary's military spending level varying contingent upon these spending levels as a proportion of the target State's spending level (See Saperstein, 1997; Richards, 2000, Introduction). Yet, Richardson produced a set of linear differential equations to model these relationships. Clearly, the extant state of the art inhibited the introduction of nonlinearity in system variable relationships.

The decade of the 1980's evidenced an increase in the number of efforts to contend with and recognize nonlinearity in political (Huckfeldt, Kohfeld and Likens, 1982; Axelrod, 1984; Saperstein, 1986; C. Brown, 1988; Saperstein and Mayer-Kress, 1988) and administrative systems (Kiel, 1989). In particular, Robert Axelrod's, The Evolution of Cooperation (1984), included agentbased and evolutionary representations of actors in simulated political environments. While the nonlinearity in Axelrod's models was not always explicit, he was attuned to the "nonlinear effects" (See Axelrod, 1984) that were likely to result from his simulations of actors altering their survival strategies over time. Axelrod's evolutionary approach coupled with the elegant simplicity of his use of the classic prisoner's dilemma model served as a foundation for the importance of nonlinear effects in dynamical models of politics. Axelrod's, work (1984) continues to be cited in a variety of 
academic disciplines as an example of the value of iterated models that generate uncertain outcomes.

It was the decade of the 1990's though that witnessed a genuine proliferation in the application of nonlinear methods to political science (Saperstein, 1990-1992, 1996, 1997; C. Brown, 1991, 1993-1995a, 1995b; Richards, 1990, 1992, 2000a, 2000b; Mayer-Kress, 1990; T. Brown, 1996; McBurnett, 1996) and public administration (Kiel, 1993, 1994; Kiel and Elliott, 1992; Kiel and Seldon, 1998). However, the use of the term proliferation must be viewed in light of the continuing dominance of linear and static methodologies in political and administrative studies. Political science, however, did produce a wide spectrum of scholarship applying nonlinear dynamics to political phenomenon. The seminal work in the 1990's of nonlinear dynamical modeling in political science though must be seen as Courtney Brown's 1995 book, Serpents in the Sand: Essays on the Nonlinear Nature of Politics and Human Destiny.

Relative to political science the literature of public administration reveals far fewer efforts to use nonlinear methods of analysis and model building. This reality, is in part, a reflection of the fact that public administration has a practical side that must appeal to practicing public managers. Clearly, most public managers are not prepared for an academic discussion of nonlinear methodologies in the social sciences. L. Douglas Kiel's 1994, Managing Chaos and Complexity in Government remains as the singular book devoted to informing both scholars and practitioners of the potential value of understanding the nonlinear dynamics of public organizations and public management. Kiel has contributed other work on the dynamics of work (1993) and with his colleagues has explored the nonlinearity in budgetary outlays (Kiel and Elliott, 1992) and the limits on managerial rationality produced by the nonlinearity in service demands on a public organizations (Kiel and Seldon, 1998). While an increasing number of public administration scholars are cognizant of the importance of incorporating nonlinearity into models of public administration (See Morcol, 1997) most of these scholars continue to apply nonlinear dynamics as metaphor (Morcol and Dennard, 2000) rather than as a means for mathematical modelling.

It is worthy of note to appreciate that a wide body of interdisciplinary scholars are now applying nonlinear techniques to the problems and potential solutions of public policy (Elliott and Kiel, 1997; Elliott and Kiel, 2000). Examples of policy problems investigated from the nonlinear dynamical perspective include teen births (Dooley, Hamilton, Cherri, West and Fisher, 1997; Hamilton and West, 2000) to earthquake disaster response (Comfort, 1999, 2000) to environmental damage and cleanup (C. Brown, 1994, 1995a).

Three major texts now exist that include state of the art nonlinear methods and mathematics in political science and public policy. These texts are Kiel and Elliott's Chaos Theory in the Social Sciences: Foundation and Applications (1996), Richards' Political Complexity: Nonlinear Models of Politics (2000) and Elliott and Kiel's Nonlinear Dynamics, Complexity and Public Policy (2000). The titles of the latter two texts just noted also reveals the expanding tendency of scholars in political science and public policy to either subsume nonlinear dynamics within the more recognizable field of "complexity" or to consider nonlinearity an essential element of the increasing interest in "complex systems".

A search for nonlinear methods as they apply to politics and public administration still represents a small minority of the literature in these fields. While not all of these emerging methods are efforts to build dynamical models of political phenomena it is clear that an increasing number of political scientists are beginning to appreciate the benefits of interjecting the "realism" of nonlinearity into model development. Political scientists and public administrationists have also not been as quick as their fellow scholars in economics to tackle the analytical challenges of nonlinearity. This is likely due to two reasons. First, economists in general are far more mathematically sophisticated than 
political scientists. And second, economists have the benefit of a wider variety of detailed and frequently produced time series data, for example stock market ticks or daily exchange rates, than do students of politics who may have only time series data based on bi-annual elections or infrequent public opinion polls.

\section{THE ARRAY OF METHODS FOR EXPLORING NONLINEARITY IN POLITICAL SCIENCE AND PUBLIC ADMINISTRATION}

Making sense of the array of methods that incorporate nonlinear relationships applied to political science and public administration can be confusing. Political scientists have defined two frameworks for classifying this body of nonlinear methods. Brown (1995a) has suggested a dichotomous approach to classifying nonlinear models based on either functional or longitudinal nonlinearity. More recently, Richards (2000a) has developed a tripartite typology of nonlinear approaches that enhances Brown's (1995a) scheme. Richards' system (2000a) views nonlinear approaches as: (1) Temporal Nonlinearity, which simply focuses on dynamics over time (the same as Brown's (1995) longitudinal nonlinearity; (2) Spatial Nonlinearity, based on search and optimization methods as "agents" or some other variable moves over some defined region, or two-dimensional computer screen; and (3) Functional Nonlinearity, which considers relationships between variables as nonlinear functions.

Naturally, as with most of our efforts to simplify the complex, even Richards' scheme fails to provide a means for making clear distinctions between the varying modeling methods employed. This of course is less the fault of the classification scheme than it is a reflection of the reality that the models used often employ more than one of the approaches to nonlinearity mentioned above. For example, a model of adaptive agents moving on a landscape may exhibit all three of the approaches to nonlinearity noted by Richards (2000a). However, since the simplification of the complex does add-value, at least as a means of adding clarity, Richards' typology will be used to present a picture of the variety of applications of nonlinear models and methods in political science and public administration.

\section{Temporal Nonlinearity: The Lessons of Time}

It is most fitting to start with applications of temporal nonlinearity in political science and public administration since this literature constitutes the majority of nonlinear studies in these fields. Within political science the largest body of literature has focused on the subfield of international relations (Saperstein, 1984, 1986, 1998; Wolfson, Puri and Martelli, 1992). The few studies of temporal nonlinearity in public administration have focused on workplace dynamics (Kiel, 1993, 1994). Temporal nonlinear models in political science generally are efforts to develop dynamical systems models of political phenomena.

The literature of nonlinear dynamics in international relations has been dominated by the work of physicist, (Alvin Saperstein, 1984, 1986a, 1986b, 1988, 1990-1992, 1996, 1997; Saperstein and Mayer-Kress, 1988). In fact, his two earliest nonlinear models of international relations appeared in the journals Nature (1984) and the American Journal of Physics (1986). The principle concern of Saperstein's work is the identification of the dynamics that lead to war and international conflict. In short, Saperstein has examined how varying nation-state behaviors interact with the responses of competing states to engender either increased instability or increased stability in nation-state relations. Saperstein's 1984 publication also appears as an early, if not the first, recognition of the potential for mathematical chaos in the temporal dynamics of political phenomena.

It is also worthy of note that political scientists such as Diana Richards (1990, 1992) have also examined the potential for mathematical chaos to arise out of the process of decision-making during 
international crises. In short, the iterative and interconnected process of strategy making can lead to chaotic dynamics as political actors try to respond to the cues of other actors.

Several political scientists have also explored the dynamics of electoral behavior using nonlinear methods (Huckfedlt, Kohfeld and Likens, 1982; C. Brown, 1991, 1993, 1995a; McBurnett, 1996). These studies range from Brown's (1991) study of electoral volatility to his later study of an electoral landslide (1993, 1995a). Brown (1993, 1995a) uses phase diagrams as a source for both hypothesis generation and testing. A related field in political studies, public opinion has also been also been explored by (Huckfeldt, Kohfeld and Likens, 1982) and McBurnett (1996). Mebane (2000) has shown through the application of differential equations that small changes in a congressional challenger's quality can destabilize an incumbent's electoral advantage.

More recent efforts to examine nonlinear temporal dynamics in political phenomena include efforts such as Brooks, Hinich and Molyneaux's (2000) investigation of how the relationships between political and economic events affect international exchange rates. This study was aimed at developing a means of "episodic nonlinear event detection" (Brooks, Hinich and Molyneaux, 2000) that, in this case, assesses nonlinearities in exchange rates and then looks "back" to identify salient political and economic events that altered exchange rates. Lohmann (2000) has examined the nonlinearities that occur over time as human informational exchange results in "informational cascades" that generate instabilities in social relationships and outcomes. Richards (2000b) has also examined the nonlinearities that occur, via a game theoretical approach that reveals that the choices of international actors may not always converge to an equilibrium.

In public administration, authors have largely focused on nonlinearities that occur in either intra or inter-organizational relationships. For example, Kiel $(1993,1994)$ has examined the dynamics of organizational outputs in light of instabilities and cycles that arise between employee time on task and results. Kiel (1994) has also examined the uncertainties of organizational improvement efforts when nonlinearities exist in the relationships between employee behavior, managerial expectations and outcomes. Groundbreaking work in the area of inter-organizational behavior has been conducted by Comfort $(1999,2000)$. Comfort has examined the interactions of the multiple agencies that respond during the peak of environmental disasters. This research has revealed both the sensitivity of and importance of information networks in effective governmental response to disasters.

\section{Spatial Nonlinearity: Order and Disorder in Space}

Studies of spatial nonlinearities in politics and public administration generally involve the examination of the behavior of either an adaptive or rational agent that seeks some optimal outcome based on their spatial relationships to other agents: Optimal outcomes may be defined as economic, behavioral, or policy outcomes that reflect the preferences of agents.

The classic work in political science examining such spatial dynamics is Schelling's study, Micromotives and Macrobehavior (1978). Schelling's research eventuated in the conclusion that choices made by individuals to live in communities with other individuals of a like race, tends to inevitably result in segregated communities. Axelrod (1984, 1997) has also developed groundbreaking work in the dynamics of alliance building based on the peaks and valleys of landscape theory. More recent analysis relevant to politics is Epstein and Axtell's (1996) agent-based modeling of how agents consume social resources on a "sugarscape".

Another simulation effort indicative of such spatial analysis is Kollman, Page and Miller's (2000) model of how "rational" citizens may optimize their own utility by relocating their household based on their preferences for local public policies. A more general approach presented by Bennett (2000) reveals the potential 
application of spatial nonlinearity on a variety of political landscapes. These applications largely revolve around coalition-building as either nation-states or individual agents engage in search regimens to discover policy preferences on a landscape that results in movement to regimes with like preferences.

Comfort's (1999, 2000) study of earthquake disasters and the concomitant response by government emergency and disaster relief agencies is a landmark in applying spatial nonlinear models to public administration behavior. Her research explores how actors on the actual physical landscape of a city behave under crisis conditions. The importance of this research is signaled by its likely value as a means for optimizing the organization of emergency resources during disasters.

Ongoing efforts to expand the array of spatial nonlinear methods to political and administrative studies are likely to be enhanced by the introduction of journal outlets such as the Journal of Artificial Societies and Social Simulation, recently established at the University of Surrey. The fact that this journal is electronic and computer-based raises interesting possibilities for social science spatial modeling. For example, one can imagine in a not too distant future that such articles will allow readers to run published simulations in real-time while also providing researchers the opportunity to tune model parameters with the aim of exploring the multiple possibilities such models should incorporate. Kiel (2000) has suggested that political and public administrative research may be greatly enhanced by expanded efforts to apply spatial models to the political and organizational landscapes that adaptive agents must explore to find optimal solutions to the challenges of political and organizational life.

\section{Functional Nonlinearity: The Hunt for Nonlinearity}

Studies of Functional nonlinearity in political science and public administration generally include attempts to either discern nonlinearities in existing data or to identify instances where nonlinear and chaotic behavior has the potential to occur. While such studies in political science remain in an embryonic stage instances of such research do exist.

One area of study directed at examining functional forms in political phenomena includes the comparison on neural network models with traditional linear statistical methods. Zeng's (2000) research with neural networks reveals the superiority of these models in terms of data-fitting to traditional statistical methods such as linear regression and logit models. Bearce (2000) has also shown the superiority of neural networks relative to traditional statistics while examining the efficacy of economic sanctions in the international arena. Another example of the analysis of functional nonlinearity is Schrodt's (2000) use of hidden Markov models to explore patterns in international crises.

If the hunt for nonlinearity in political science is still in its embryonic stage then the hunt for nonlinearity in public administration still waits for fertilization. While nonlinear approaches have been employed in public administration modeling, much of the work examining nonlinear dynamics in public administration, assume functional nonlinearity, yet epistemologically remain at the metaphorical stage of exploration (See Morcol and Dennard, 2000).

One example of the search for functional nonlinearity in the literature of public administration is evidenced in Kiel and Seldon's (1998) study. This research examined government service requests in an effort to determine the mathematical structure of the evolution of such service requests. Another more sophisticated effort includes Carpenter's (2000) examination of bureaucratic agency lifetimes. This research used nonlinear estimators to test the "hazards" to agency survival.

While those research efforts categorized as explorations of "functional nonlinearity" remain a minority of nonlinear studies in political and administrative research this area has considerable potential payoffs. Knowledge of the basic mathematical structure of political and administrative 
networks may eventuate in the discovery of underlying patterns that may generate knowledge in areas such as expected levels of uncertainty that may lead to improved theory in political and administrative studies.

\section{DISCRETE AND CONTINUOUS TIME MODELS IN POLITICAL SCIENCE AND PUBLIC ADMINISTRATION}

The work of political scientists and public administrationists over the last twenty years does show a growing body of literature using mathematical models that incorporate nonlinearity. While this is a growing body of literature it remains as a rather clear and unique niche for research.

It is worthy of note that a divergence of opinion exists among political scientists as to the relative merits of continuous and discrete time models of nonlinear political phenomena. It must be remembered that at this point in the evolution of political science as an intellectual enterprise a minority of political scientists possess advanced mathematical skills. If we define knowledge of calculus as such an advanced skill, then only a minority of political scientists have a strong knowledge of calculus. This group of scholars though are quite familiar with differential equations and models of continuous time. Perhaps, unfortunately these same scholars are less familiar with the discrete time models of difference equations. Thus, continuous time models relying on differential equations dominate both the dynamical and nonlinear dynamical models developed by political scientists.

Courtney Brown (1995a), is perhaps the most vocal proponent, among political scientists, of the superior value of continuous time models relative to discrete models. Brown believes that the time distance between most data points in political data, be it the time span between the taking of public opinion polls or the distance from one congressional election to another, neglects the reality that nonlinear behavior may occur between data (time) points. Brown sees this problem as particularly acute when considering the widespread use of cross-sectional studies in political science. From this perspective, only continuous time models can capture fluid and potentially nonlinear political phenomena such as attitudinal shifts.

Naturally, the reality of modeling is that all of our known methods include inherent limitations. Clearly, discrete time models are limited by unknown or uncollected data that exist between the data points collected in typical political studies. Yet, discrete time models offer the potential to produce a wider set of qualitative behaviors over time relative to continuous time models (Huckfeldt, Kohfeld and Likens, 1982, p. 90). Thus discrete models are capable of producing a larger range of behaviors that are more likely to simulate the complexity of the social realm.

Perhaps, more importantly discrete models satisfy the demands of Occam's razor. In short, discrete models represent more parsimonious approaches that define the "elegance in simplicity" that should motivate the model building process. This recognition is important for two reasons. First, the expanding recognition that complex behavior may be generated by "simple rules" emphasizes the potential importance of the use of discrete time models. And second, the slightly more approachable and understandable mathematics of difference equations, relative to differential equations, may energize the mathematically disenfranchised to investigate the potential applications of discrete dynamical models. Yet, continuous time models continue to serve as the dominant modality not only due to the strength of Brown's (1995a) argument but also because these methods are simply more widely recognized and known among political scientists.

\section{Dynamical Models in Discrete Time}

The following two sections of this article present dynamical models in political science and public administration. The reader will note the asymmetry in the display of three mathematical models from the domain of political science and only one 
from public administration. This asymmetry is intentional and shows that considerably more work in nonlinear dynamical modeling has been done in the field of political science relative to public administration. The practical side of public administration may limit such efforts as many public administration scholars believe that their work must have relevance to practitioners who rarely find "value" in such models.

As noted previously, the most prolific publisher in the applications of nonlinear dynamics to political phenomena is the physicist Alvin Saperstein. Dr. Saperstein's works have focused on the potentialities for arms races to produce unstable international dynamics and thus the likelihood of war. Saperstein has ventured to examine a variety of questions based on the assumption of nonlinear relationships between competing powers (1996).

One of the more macroscopic and consistent questions in international relations concerns whether democracies or autocracies are relatively more prone to war. Saperstein handles the question of political structure and the likelihood of war with the production of a "procurement recursion relation" (1996, p. 156) between two nation states. These relations are based on a "fear and loathing" coefficient founded on each nation's perception of the military procurement behavior of its competitor nation. In short, each nation's (nation $X$ ) arms procurement at time $X_{t+1}$ is a proportional response to the amount its arms stocks were exceeded by its competitor's (nation $Y$ ) arms stocks at time $Y_{t}$, thus: $Y_{n}-X_{n}$. The fear and loathing coefficient $a$ thus serves to constitute the proportionality constant of arms buildup of $a_{x y}$ for nation $X$ and $a_{y x}$ for arms buildup in nation $Y$.

The reality of economic constraints is also included in Saperstein's nonlinear adaptation of a Richardson-like arms race model. Since armament procurement cannot expand more than the total economy will allow a smooth economic cutoff function is included in the model. Thus $C_{x}$ is the maximum arms expenditure for nation $X$. Thus the smooth economic cut-off function is
(Saperstein, 1996, p. 156):

$$
\theta\left(1-\Delta X / C_{x}\right)=\left(1-\Delta X / C_{x}\right) \theta\left(1-\Delta X / C_{x}\right) .
$$

The unit step function is $\theta$ thus, $(\theta(\eta)=1$ for $\eta>1,=0$ otherwise). Finally, build-down of armaments can occur if a nation's confidence warrants such action. The confidence coefficient for build-down, thus results in a proportionality parameter that is the inverse of the fear and loathing coefficient.

Thus this tit-for-tat model of arms procurement results in the following set of recursion relations (Eq. (1)). Build-ups and build-downs thus change between $X$ and $Y$ based on arms stock in the previous year:

$$
\begin{aligned}
X_{n+1}=X_{n}+a_{x y} Y_{n}\left(Y_{n}-X_{n}\right) \tilde{\theta} & \left(1-\left[X_{n}+1-X_{n}\right] / C_{x}\right) \theta\left(Y_{n}-X_{n}\right) \\
& -\frac{1}{a_{x y}} X_{n}\left(X_{n}-Y_{n}\right) \theta\left(X_{n}-Y_{n}\right) \\
Y_{n+1}= & Y_{n}+a_{y x} X_{n}\left(X_{n}-Y_{n}\right) \tilde{\theta} \\
& \left(1-\left[Y_{n}+1-Y_{n}\right] / C_{y}\right) \theta\left(X_{n}-Y_{n}\right) \\
& -\frac{1}{a_{x y}} Y_{n}\left(Y_{n}-X_{n}\right) \theta\left(Y_{n}-X_{n}\right)
\end{aligned}
$$

Saperstein iterated these relations using a spreadsheet starting with arbitrary initial conditions for both $X$ and $Y$. Iterating the model to a large $n(n=100)$ he then calculated Lyapunov coefficients. Since large values of the fear and loathing coefficient result in more arms build-up and thus a greater region of instability, Saperstein concludes that international systems with more autocratic states are more likely to generate war than systems with more democratic states. This us due to the likelihood of democratic states sharing information regarding national intent.

A relatively sophisticated effort to apply nonlinear dynamic modeling to the subject matter of public administration was presented by Huckfeldt, Kohfeld, and Likens in 1982 (1982, pp. 65-81). These models focus on "budgetary dynamics", an elemental aspect of the subject matter of public 
administration. These scholars developed a discrete model of budgetary dynamics based on the competitive interdependence, yet restricted competition, between government agencies as agencies compete for financial resources. A basic predator/ prey model is produced which in the vernacular of politics may be seen as a "zero-sum" game. The budgetary gain, or victory, of one agency likely occurs at the financial loss to another agency. A model consistent with the budgeting literature of "incremental" increases or decreases in budgets is used to constrain explosive dynamics.

Five basic assumptions drive the models presented below (Huckfeldt, Kohfeld and Likens, 1982). Initially, the inherent limits of budgetary resources constrains any agency's budget share to some upper limit. Next, some level of budgetary constraint is necessary since agencies are rarely eliminated. Third, some agencies can be assumed to have a lower limit on resources. For example, national defense can always assume some share of government spending. Fourth, the reality of budgeting reveals that agencies generally "satisfice" and never obtain either maximal or minimal levels of financial resources. Finally, future levels of agency spending are generally contingent upon current funding levels.

The coupled cubic equations resulting from these assumed budgetary dynamics are shown for two agencies, $X$ and $Y$, in (Eq. (2)).

$$
\begin{aligned}
\Delta X_{t} & =\left[p_{x}\left(L_{x}-X_{t}\right)-c_{y} Y_{t}\right] X_{t}\left[X_{t}-B_{x}\right] \\
\Delta Y_{t} & =\left[p_{y}\left(L_{y}-Y_{t}\right)-c_{x} X_{t}\right] Y_{t}\left[Y_{t}-B_{y}\right]
\end{aligned}
$$

Both of these equations include four variables that enhance model dynamics. The variable $L$ represents the natural agency budget upper limit, while $B$ represents a lower limit of funding. The terms $p$ and $c$ represent parameter values for an agency's average rate of success in securing resources $(p)$ and $(c)$ a discounting factor that represents the a characteristic rate of the current budgetary success of the competing agencies, $X$ and $Y$.

The logic of the equations thus follows that $\Delta X_{t}$ represents the change in the rate of budgetary "success" of agency $X$, that is proportional to a typical rate $p_{x}$ to the difference between the agency's upper limit, $L_{x}$, and the agency's current level of funding, $X_{t}$. This result is combined with the discounting factor $c_{y}$, that results from competition with agency $Y$ and functions proportionally to the budget level of $X_{t}$. The parameter $c_{y}$ thus functions as a characteristic and proportional rate of the funding level of each agency at the discrete time period. The second minus sign in the equation reveals the zero-sum nature of the model by noting that agency $Y$ 's budget necessarily takes from the budget of agency $X$. The extreme right hand-side of the equation shows that if any agency budget is decreasing towards its lower bound and $\left[X_{t}-B_{x}\right]$ is becoming increasingly small then the interaction between the agency competition and thus budgets decreases.

The multiple outcomes generated by this model are quite intriguing. Nine identifiable equilibria may exist with this iterative model. These stabilizing results range from those when both agencies are abolished to more likely instances of stability when both agencies reach a stable equilibrium of funding between their natural upper and lower limits of funding.

\section{Dynamical Models in Continuous Time}

As noted previously, continuous time methods are the dominant method for modeling nonlinear dynamical systems in political and governmental studies. Professor Courtney Brown's leadership position in nonlinear dynamical modeling warrants the exegesis of the following two nonlinear models of political phenomena that he developed.

The series of equations depicted in (Eq. (3)) is Brown's (1994) effort to develop a model of environmental damage based on partisan control and public opinion. In short, this models depicts how partisan political changes in the holding of the U.S. presidency coupled with citizen attitudes toward environmental cleanup and expected public policies can serve to inhibit or engender environmental damage. This model assumes that 
democratic regimes will accept more social costs to limit environmental damage while republican held whitehouses will focus on economic growth leading to greater environmental damage.

This model includes three basic state variables. These variables are environmental damage $(X)$, public concern for the environment $(Y)$ and spending for environmental cleanup $(Z)$. The first equation expresses the change in environmental damage. The three parameter values represent $(r)$ the pollution growth rate, $(p)$ the effectiveness of government policies to reduce environmental damage, and $(k)$ a decay value that reduces environmental damage based on current values of that damage.

The second equation reveals the change in public concern for the environment. The variable $X_{\text {old }}$ defines a lagged value for environmental concern since public opinion usually reacts to rather than predicts environmental damage. This equation shows the shifting dynamic between public concern and costs revealing that as costs rise public concern for the environment is likely to diminish.

Equation three reveals the dynamics of government environmental spending. Again, a similar logic as developed in the second equation follows. As public concern and environmental damage both increase spending increases to some limit. Increases in spending that reach near this limit value then serve to diminish public concern resulting in decreasing spending on the environment. These first three equations interact over time and continuously in which cyclical behavior among all of the state variables is a potential behavior.

The final equation reveals how partisan goals (simplified to mean control of the presidency) function to change environmental policy. The variables $g_{\text {dem }}$ and $g_{\text {rep }}$ represent the "ideal policy response goal" (Brown, 1994, p. 299) of either a democratic or republican administration. Remembering that $p$ is a parameter for the effectiveness of government policy, then $e$ is a parameter that defines the speed of policy changes toward the partisan goals of the standing administration.
Given nonlinear assumptions concerning the potential for environmental damage embedded in Brown's variables, the graphical results of his models results are quite stark. Shifts in policy regimes supported by varying levels of public support and concomitant government spending can create dramatic changes in environmental damage. If the interaction between public concern and government spending for the environment is the oft-noted metaphorical "butterfly", then the resulting metaphorical "tornado" is the reality of damage to an environmental system in which nonlinear interactions are just beginning to be understood.

$$
\begin{aligned}
d X / d t & =r X(1-X)-p X Y-k X \\
d Y / d t & =X_{\mathrm{old}}(1-Y)-Z \\
d Z / d t & =X Y(1-Z)-Z \\
d p / d t & =e p\left(g_{\text {dem }}+g_{\text {rep }}-p\right)
\end{aligned}
$$

Another field within political science that is amenable to dynamical modeling is electoral studies. Electoral studies is a ripe area for nonlinear modeling since elections are viewed longitudinally and generate numerous data points ranging from polling data to changes in partisan attachments. Again, Courtney Brown has developed an elegant model of an electoral phenomenon, that of an electoral landslide. In particular, Brown has attempted to model the U.S. national Democratic landslide of 1964 (1993, 1995a).

In the model shown (Eq. (4)) below Brown (1995a, pp. 55-83) presents mirror-image equations of the dynamics of democratic and republican party support. The result of both equations is the change in either $(D)$ the proportion of the electorate supporting the Democratic party or $(R)$ the proportion of the electorate supporting the Republican party. These equations are best understood by first reviewing the variables in the second set of parentheses on the right hand side of the equations. The small letters throughout the equations represent parameter values defining the limits of and changes in partisan support. Thus 
the term $q(D / R)$ refers to the proportion of the electorate of each party affiliation. The term $w D R$ is a multiplicative term defining the probability of interaction between members of the diverse parties altering individual party attachments, much like a contagion effect. The term $u D$ defines the growth in Democratic support based on preexisting levels of Democratic support.

The first parenthesis in this equation incorporates the "bunching" effect that occurs" as one party tends to dominate an election cycle. The number 1 specifies the model in a normal nonaccelerated form, while the parameter $j$ reveals the acceleration in momentum of party support. The term $y D^{2}$ includes the parameter $y$ that serves to mediate the acceleration that results from the squaring of $D$ that represents the "bunching" or bandwagon affect.

The variable $v N$ is the proportion of nonvoting eligible voters that is parameterized by the constant $v$, since this bloc of nonvoters is generally stable. Finally, the remainder of the equation outside of the brackets $(1-D) D$ defines the growth and decay of party support using the logistic modality.

These two differential equations thus represent an interdependent system. Parameter estimates of the equations were produced using nonlinear regression techniques. These estimates were derived from the approximately 3000 counties in the U.S. for presidential election years 1960 and 1964. For non-southern countries Brown's model explained approximately 80 percent of the variance for both Democrats and Republicans (Brown, 1995a, p. 66). The fit for the southern U.S. countries was not as convincing, however, this may have to do with the longer standing institutionalization of party line voting in the South.

$$
\begin{aligned}
d D / d t= & {\left[\left(1+j D+y D^{2}\right)(q(D / R)\right.} \\
& +w D R+u D)+v N](1-D) D \\
d R / d t= & {\left[\left(1+p R+s R^{2}\right)(f(R / D)\right.} \\
& +a R D+e R)+g N](1-R) R
\end{aligned}
$$

In general, Brown's work focuses on the kinds of data that are most available to political scientists interested in nonlinear modeling. These data are the attitudinal and electoral studies that are essential to understanding the nonlinearity that appears inherent in an open and democratic society in which multiple interests compete to define agendas and shape attitudes. Improved knowledge in these areas is likely to be one of the worthwhile outcomes of an expanded application of nonlinear dynamical models of political and public administrative phenomena.

\section{CONCLUSION - VENTURING A PREDICTION IN AN UNPREDICTABLE WORLD}

When venturing a guess concerning the evolution of the academic enterprise one must be cognizant of Thomas Kuhn's (1962) admonition that scientific revolutions are more matters of incremental advance rather than rapid change. The evolution of nonlinear dynamical modeling in political science and public administration seems to typify Kuhn's view of time and change. Each of the scholars engaged in the "nonlinear enterprise" likely can speak eloquently of their own stories of fighting off the slings and arrows that come with trying to publish papers using nonlinear methods. Thus whether one argues for nonlinear dynamics as "revolution" or for the "incremental advancement" as a definition of nonlinear dynamics, resistance exists either through ignorance or via the human tendency to stick with that which is known and comfortable.

At present few doctoral programs in political science of public administration include nonlinear dynamical methods of analysis in methods courses. Graduate students receiving training in nonlinear methods usually receive such training either by a serendipitous acquaintance with a faculty member exploring such topics or, in even more rare circumstances, by the student's own effort to seek out a graduate program in which faculty are 
recognized experts in nonlinear methods of analysis. In order to resolve this problem organized efforts on the part of political scientists and public administrationists are necessary to promote greater knowledge of nonlinear methods and models and to promote such methods in both professional meetings and in graduate methods curricula.

On a more optimistic note, an effort is underway in public administration to push scholars to develop more sophisticated and mathematical models (See Lynn, 2000). Morcol and Dennard's (2000) forthcoming edited volume applying the "new sciences" to public administration, while generally devoid of mathematical models, may also serve as a theoretical base for the development of nonlinear dynamical models in public administration. The recent publication of a nonlinear model of general public management (O'Toole and Meier, 1999) in a leading journal in the field again shows the growing recognition of the importance and potential benefit of such modeling effort.

One lingering challenge for incorporating more nonlinear research and modeling into political and public administrative research, properly noted by Richards (2000), is the lack of "industry standards" for nonlinear analysis. There simply is no generally agreed upon set of specific nonlinear methods that is generally accepted by social scientists. This reality makes it difficult for many junior scholars to venture into a field that lacks the comfort of the accepted conventions of traditional statistical approaches.

Perhaps the most hopeful note for an increase in the recognition of the mathematics of nonlinearity in political and public administration phenomena is signaled in the number of established scholars who contributed to the recent edited book on nonlinear methods in political science by Diana Richards (2000). The fact that three edited volumes Kiel and Elliott (1996); Richards (2000); Elliot and Kiel (2000) now exist also shows that a body of literature is developing that can serve as a basis for emerging scholars to take upon the challenge of nonlinearity in politics and public administration.
The increasing recognition of the relevance of the sciences of complexity to political science and public administration should also serve to advance the nonlinear agenda. The Princeton University series on Complexity has already contributed System Effects (1997); Axelrods' The Complexity of Cooperation (1997), and Cederman's Emergent Actors in World Politics: How States and Nations Develop and Dissolve (1997). John Holland's (1995) suggestion that agent-based simulation serve as a "flight simulator" for public policy actors may also serve to move the nonlinear agenda forward.

Furthermore, the expanding array of methods employed by political scientists and public administration scholars and the increasing level of technical sophistication of these methods suggest that momentum for nonlinear analysis is increasing (See Richards, 2000). The increasing number of papers that examine agent-based behavior (See Richards, 2000) also holds considerable promise for meeting Epstein and Axtell's challenge to build "social science from the ground up" (1996).

Finally, it is increasingly apparent that the evolution of life on the planet is a result of nonlinear interactions that generate instabilities in dissipative systems. These instabilities may result in complexities in social systems behavior that comprise the very challenges of attempting to understand the vagaries of political and administrative phenomena (Schieve and Allen, 1982). It is also clear that understanding these complexities will be a major source of the power of nationstates in the future (Pagels, 1988). In a world in which information leaks and technology is readily transported these social resources of information and technology may expedite nonlinear amplifications that threaten both local and global stability. Given this reality, political scientists and public administrationists are likely to have an increasing interest in studying the nonlinear dynamics of a world in which nonlinearity poses both an opportunity for and a threat to institutions, nation-states and the global community. 


\section{References}

Axelrod, R. (1984) The Evolution of Cooperation. New York: Basic Books.

Axelrod, R. (1997) The Complexity of Cooperation: AgentBased Models of Competition and Collaboration. Princeton, NJ: Princeton University Press.

Bearce, D. (2000) Economic Sanctions and Neural Networks: Forecasting Effectiveness and Reconsidering Cooperation. In: Political Complexity: Nonlinear Models of Politics, Richards, D. Ed., Ann Arbor: University of Michigan Press. pp. 269-295.

Bennett, D. S. (2000) Landscapes as Analogues of Political Phenomena. In: Political Complexity: Nonlinear Models of Politics, Richards, D. Ed., Ann Arbor: University of Michigan Press. pp. 46-79.

Brooks, C., Hinich, M. and Molyneaux, R. (2000) Episodic Nonlinear Event Detection: Political Epochs in Exchange Rates. In: Political Complexity: Nonlinear Models of Politics, Richards, D. Ed., Ann Arbor: University of Michigan Press. pp. $83-98$.

Brown, C. (1988) Mass Dynamics of U.S. Presidential Competitions, 1928-36. American Political Science Review, 82, $1153-1181$.

Brown, C. (1991) Ballots of Tumult: A Portrait of Volatility in American Voting. Ann Arbor: University of Michigan Press.

Brown, C. (1993) Nonlinear Transformation in a Landslide: Johnson and Goldwater in 1964. American Journal of Political Science, 37, 582-609.

Brown, C. (1994) Politics and the Environment: Nonlinear Instabilities Dominate. American Political Science Review, 37, $292-303$.

Brown, C. (1995a) Serpents in the Sand. Ann Arbor: University of Michigan Press.

Brown, C. (1995b) Chaos and Catastrophe Theories. Thousand Oaks, CA: Sage Publications.

Brown, C. (1988) Mass Dynamics of U.S. Presidential Competitions, 1928-36. American Political Science Review, 82, $1153-1181$.

Brown, T. (1996) Nonlinear Politics. In: Chaos Theory in the Social Sciences: Foundations and Applications, Kiel, L. D. and Elliott, E. Eds., pp. 119-138, Ann Arbor: University of Michigan Press.

Carpenter, D. (2000) Stochastic Prediction and Estimation of Nonlinear Political Durations. In: Political Complexity: Nonlinear Models of Politics, Richards, D. Ed., Ann Arbor: University of Michigan Press. pp. 209-238.

Cederman, L. E. (1997) Emergent Actors in World Politics: How State and Nations Develop and Dissolve. Princeton, NJ: Princeton University Press.

Comfort, L. (1999) Shared Risk: Complex Systems in Seismic Response. London: Lawrence Erlbaum.

Comfort, L. (2000) Nonlinear Dynamics in Disaster Response: The Northridge California Earthquake, January 17, 1994. In: Nonlinear Dynamics, Complexity and Public Policy, Elliott, E. and Kiel, L. D. (Eds.), pp. 139-152.

Dooley, K., Hamilton, P., Cherri, M., West, B. and Fisher, P. (2000) Chaotic Behavior in Society: Adolescent Childbearing in Texas, 1964-1990. In: Chaos, Complexity and Sociology: Myths, Models and Theories (Eve, R., Horsfall, S. and Lee, M. Eds.). pp. 243-268, Thousand Oaks, CA: Sage.

Elliott, E. and Kiel, L. D. (1997) Nonlinear Dynamics, Complexity and Public Policy: Use, Misuse and Applicability. In: Chaos, Complexity and Sociology: Myths, Models, and Theories (Eve, R., Horsfall, S. and Lee, M. Eds.). pp. 64-78, Thousand Oaks, CA: Sage.

Elliott, E. and Kiel, L. D. (1999) Nonlinear Dynamics, Complexity and Public Policy. Commack, NY: Nova Science.

Epstein, J. and Axtell, R. (2000) Growing Artificial Societies: Social Science from the Ground Up. Cambridge, MA: MIT Press.

Hamilton, P. and West, B. (2000) Teenage Pregnancy. Nonlinear Dynamics, Complexity and Public Policy. Commack, NY: Nova Science. pp. 97-111.

Holland, J. (1995) Hidden Order: How Adaptation Builds Complexity. Reading, MA: Addison-Wesley.

Huckfeldt, R. R., Kohlfeld, C. W. and Likens, T. (1982) Dynamics Modeling: An Introduction. Newbury Park, CA: Sage Publications.

Jantsch, E. (1980) The Self Organizing Universe: Scientific and Human Implications of the Emerging Paradigm of Evolution. Oxford: Pergamon Press.

Jervis, R. (1997) System Effects. Princeton, NJ: Princeton University Press.

Kiel, L. D. (1989) Nonequilibrium Theory and Its Implications for Public Administration. Public Administration Review, 49, $544-551$.

Kiel, L. D. (1993) Nonlinear Dynamical Analysis: Assessing Systems Concepts in a Government Agency. Public Administration Review, 53, 143-153.

Kiel, L. D. (1994) Managing Chaos and Complexity in Government: A New Paradigm for Managing Change, Innovation and Organizational Renewal. San Francisco: Jossey-Bass: San Fransisco.

Kiel, L. D. and Elliott, E. (1992) Budgets as Dynamic Systems: Time, Chance, Variation and Budget Heuristics. Journal of Public Administration Research and Theory, 2, 139-156.

Kiel, L. D. and Seldon, B. (1998) Measuring Temporal Complexity in the External Environment: Nonlinearity and the Bounds of Rational Action. American Review of Public Administration, 28, 246-265.

Kollman, K., Miller, J. and Page, S. (2000) Consequences of Nonlinear Preferences in a Federal System. In: Political Complexity: Nonlinear Models of Politics, Richards, D. Ed., Ann Arbor: University of Michigan Press. pp. 23-45.

Kuhn, T. (1962) The Structure of Scientific Revolutions. Chicago: University of Chicago Press.

Lohmann, S. (2000) I Know You Know She Knows We Know You Know They Know: Common Knowledge and the Unpredictability of Informational Cascades. In: Political Complexity: Nonlinear Models of Politics, Richards, D. Ed., Ann Arbor: University of Michigan Press. pp. 137-173.

Lynn, L. Jr. (Ed.) (2000) Models and Methods for the Empirical Study of Governance and Public Management. Washington, DC: Georgetown University Press.

Mayer-Kress, G. (1990) A Nonlinear Dynamical Systems Approach to International Security. In: The Ubiquity of Chaos, Krasner, S. Ed., American Association for the Advancement of Science, Washington D.C., pp. 181-196.

McBurnett, M. (1997) Complexity in the Evolution of Public Opinion. In: Chaos Theory in the Social Sciences: Foundations and Applications. (Douglas, L. Kiel and Euel Elliott, Eds.). University of Michigan Press, Ann Arbor, Michigan, pp. $165-198$.

Mebane, W. (2000) Congressional Campaign Contributions, District Service and Electoral Outcomes in the United States: Statistical Tests of a Formal Game Model with Nonlinear Dynamics. In: Political Complexity: Nonlinear Models of 
Politics, Richards, D. Ed., Ann Arbor: University of Michigan Press. pp. 99-136.

Mirowski, P. (1989) More Heat Than Light, Economics as Social Physics: Physics as Nature's Economy. Cambridge: Cambridge University Press.

Morcol, G. (Ed.) (1997) Symposium: Learning from Natural Sciences. Administrative Theory and Praxis, 19(3), 299-394.

Morcol, G. and Dennard, L. Eds. (2000) The New Sciences and Public Administration. Chatelaine Pubs.

O'Toole, L. and Meier, K. (1999) Modeling the Impact of Public Management: Implications of Structural Context. Journal of Public Administration Theory and Research, 9, $505-526$.

Pagels, H. (1988) The Dreams of Reason. New York: Simon and Schuster.

Rice, S. (1928) Quantitative Methods in Politics. New York: Russell \& Russell.

Richards, D. (1990) Is Strategic Decision Making Chaotic? Behavioral Science, 35, 219-232.

Richards, D. (1992) Spatial Correlation Test for Chaotic Dynamics in Political Science. American Journal of Political Science, 36, 1047-1069.

Richards, D. (2000a) Introduction. In: Political Complexity: Nonlinear Models of Politics, Richards, D. (Ed.) pp. 1-22, Ann Arbor: University of Michigan Press.

Richards, D. (2000b) Optimizing, Strategizing, and Recognizing: Learning in a Dynamic Social Environment. In: Political Complexity: Nonlinear Models of Politics, Richards, D. (Ed.), pp. 331-341, Ann Arbor: University of Michigan Press.

Richardson, L. (1960a) Arms and Insecurity. Pittsburgh, PA: Boxwood.

Richardson, L. (1960b) Statistics of Deadly Quarrels. Pittsburgh, PA: Boxwood.

Saperstein, A. (1984) Chaos-A Model for the Outbreak of War. Nature, 309, 303-305.

Saperstein, A. (1986a) Predictability, Chaos and the Transition to War. Bulletin of Peace Proposals, 17, 87-93.

Saperstein, A. (1986b) Fluid Dynamic and Kinetic Theory Models for a Nonprovocative Land Defense of Central Europe. American Journal of Physics, 54, 607-611.
Saperstein, A. and Mayer-Kress, G. (1988) A Nonlinear Dynamical Model of the Impact of S. D. I. on the Arms Race. Journal of Conflict Resolution, 35, 636-70.

Saperstein, A. (1990) Chaos and the Making of International Security Policy. In: The Ubiquity of Chaos (Saul Krasner, Ed.). American Association for the Advancement of Science, Washington D.C., pp. 167-180.

Saperstein, A. (1991) The Long Peace: Result of a Bi-polar Competitive World? Journal of Conflict Resolution, 35, 68 - 79.

Saperstein, A. (1992) Alliance Building versus Independent Action: A Nonlinear Approach to Comparative International Stability. Journal of Conflict Resolution, 36, 518-545.

Saperstein, A. (1996) The Prediction of Unpredictability: Applications of the New Paradigm of Chaos in Dynamical Systems to the Old Problem of the Stability of a System of Hostile Nations. In: Chaos Theory in the Social Sciences: Foundations and Applications (Douglas, L. Kiel and Euel Elliott, Eds.). University of Michigan Press: Ann Arbor, Michigan, pp. 139-164.

Saperstein, A. (1997) The Origins of Order and Disorder in Physical and Social Determinsitic Systems. In: Chaos, Complexity and Sociology: Myths, Models and Theories, Eve, R., Horsfall, S. and Lee, M. (Eds.), pp. 102-122.

Schelling, T. (1978) Micromotives and Macrobehavior. New York: Norton.

Schieve, W. and Allen, P. (1982) Self-Organization and Dissipative Structures: Applications in the Physical and Social Sciences. Austin: University of Texas Press.

Schrodt, P. (2000) Pattern Recognition of International Crises using Hidden Markov Models. In: Political Complexity: Nonlinear Models of Politics, Richards, D. Ed., Ann Arbor: University of Michigan Press. pp. 296-328.

Simon, H. (1957) Models of Man: Social and Rational. New York: Wiley.

Wolfson, M., Puri, A. and Martelli, M. (1992) The Nonlinear Dynamics of International Conflict. Journal of Conflict Resolution, 36, 119-149.

Zeng, L. (2000) Neural Network Models for Political Analysis. In: Political Complexity: Nonlinear Models of Politics, Richards, D. (Ed.), pp. 239-268, Ann Arbor: University of Michigan Press. 


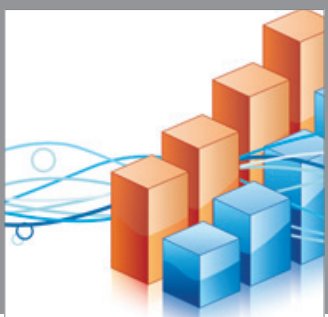

Advances in

Operations Research

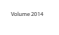

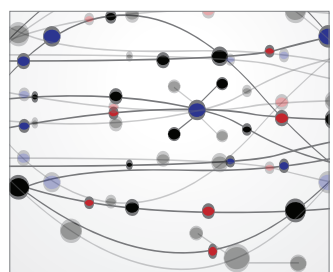

\section{The Scientific} World Journal
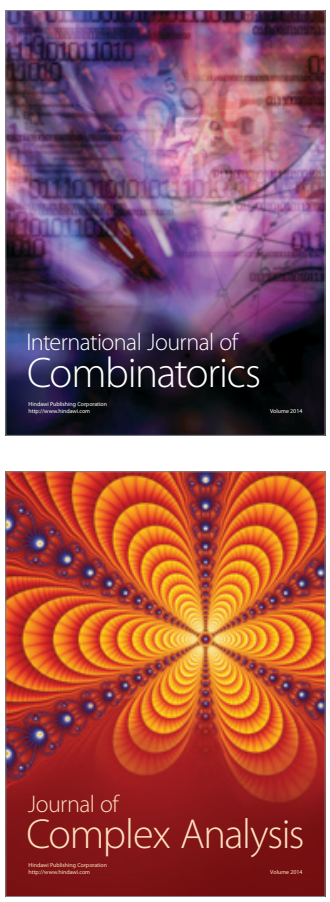

International Journal of

Mathematics and

Mathematical

Sciences
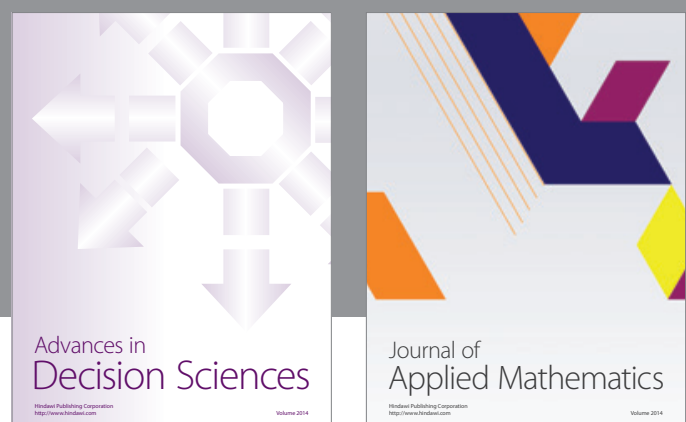

Journal of

Applied Mathematics
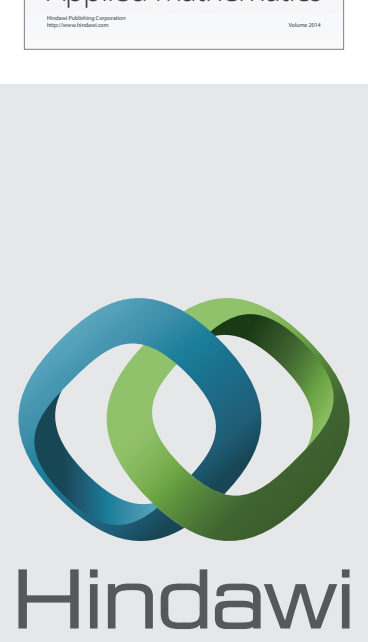

Submit your manuscripts at http://www.hindawi.com
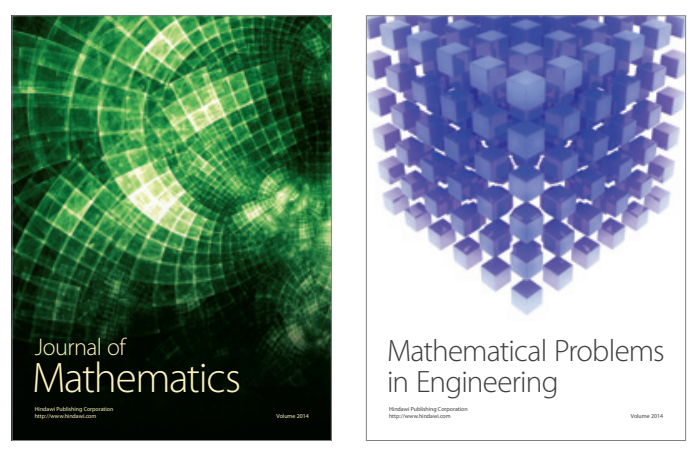

Mathematical Problems in Engineering
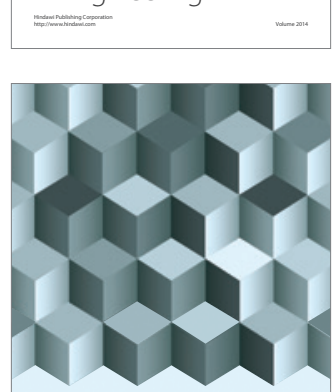

Journal of

Function Spaces
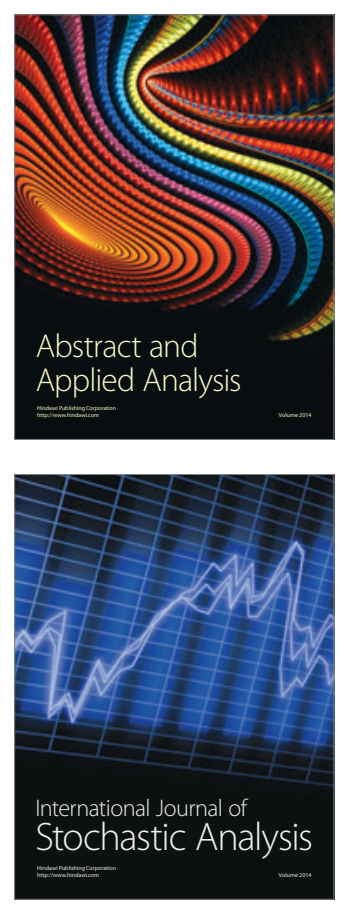

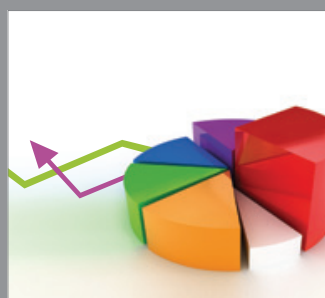

ournal of

Probability and Statistics

Promensencen
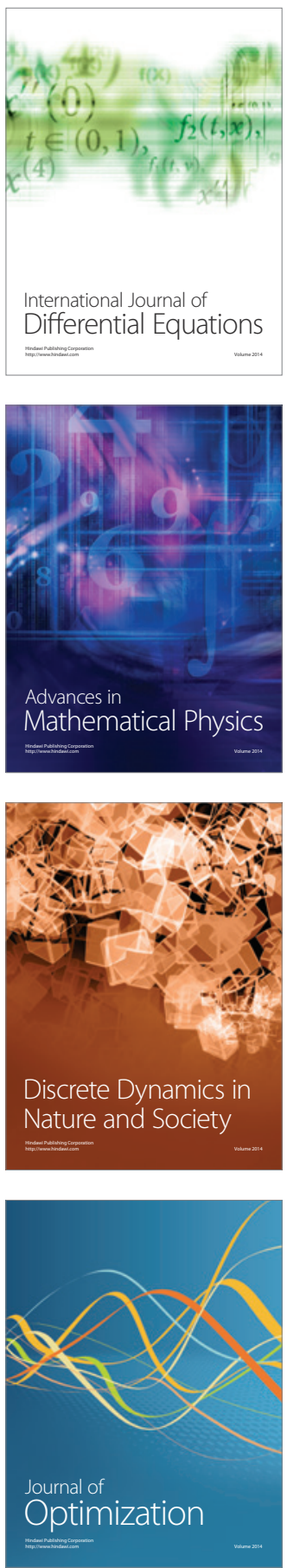